\title{
High prevalence of arrhythmias in elderly male athletes with a lifelong history of regular strenuous exercise
}

\author{
K Jensen-Urstad, F Bouvier, B Saltin, M Jensen-Urstad
}

\begin{abstract}
Objective-To characterise cardiac arrhythmias and cardiac autonomic function in 11 elderly men (mean (SD) age 73.2 (2.8) years) with a lifelong history of regular very strenuous exercise. A control group of 12 healthy sedentary or moderately physically active men (74.5 (2.7) years) was also studied.

Design-48 hour ambulatory electrocardiograms were recorded. Cardiac autonomic function was estimated from power spectral analysis of heart rate variability. Maximal oxygen uptake during treadmill exercise testing was $2.91 \quad(0.52) 1 \quad$ (41 (7) $\mathrm{ml} / \mathrm{kg}$ ).

Results-Nine of 11 athletes had complex ventricular arrhythmias compared with five of 12 controls. Seven athletes but none of the controls had episodes of heart rate below 40 beats/min and two athletes had RR intervals longer than two seconds. Heart rate variability in the athletes was higher than in the controls.

Conclusions-Elderly athletes with a lifelong training history seem to have more complex arrhythmias and profound bradyarrhythmias than do healthy elderly controls, which may increase the risk of sudden cardiac death. In contrast, the age related decrease in heart rate variability seems to be retarded, which has a positive prognostic value and may decrease the risk of life threatening ventricular arrhythmias.
\end{abstract}

(Heart 1998;79:161-164)

Physiology, Söder

Hospital, Karolinska

Institute, Stockholm,

Sweden

K Jensen-Urstad

F Bouvier

Department of Physiology and Pharmacology III, Karolinska Institute B Saltin

Department of Cardiology, Huddinge University Hospital, Karolinska Institute $M$ Jensen-Urstad

Correspondence to: $\mathrm{Dr}$ Jensen-Urstad, Department of Cardiology, Huddinge University Hospital, S-141 86 Huddinge, Sweden.

Accepted for publication 15 October 1997 prevalence of complex ventricular extrasystoles in runners with a mean age of 56 years was $10 \%{ }^{7}$

Power spectral analysis of heart rate variability, beat to beat variations in the $\mathrm{R}-\mathrm{R}$ interval length, is a tool for estimating cardiac autonomic function in patients with different cardiac and autonomic disorders, as well as in normal individuals. ${ }^{8}$ Low heart rate variability in postmyocardial infarction patients is associated with an increased risk of sudden cardiac death. ${ }^{9-11}$ Studies of young athletes have shown increased heart rate variability in all spectral bands, supposedly reflecting parasympathetic and sympathetic activities. ${ }^{12-14}$ Sachnoff et al found evidence of increased vagal tone in the time but not in the frequency domain measures of heart rate variability. ${ }^{15}$ Like other autonomic function tests, ${ }^{16}$ heart rate variability decreases with age. ${ }^{17}$ Whether strenuous exercise can retard this process is not known.

This study aimed at characterising cardiac arrhythmias, as detected by 48 hour ambulatory electrocardiography, estimating cardiac autonomic function by power spectral analysis of heart rate variability, and examining a possible relation between these variables in elderly men with a lifelong history of regular very strenuous exercise.

\section{Patients and methods}

PATIENTS

Nine orienteerers and two runners with a lifelong history of intensive running (all men; mean (SD) age 73.2 (2.8) years) were studied. Since the ages of 15-25 years they had been and were still among the best athletes in their respective age groups. At the time of investigation all participants were undertaking strenuous exercise for three to seven hours each week. All participants underwent a graded maximal bicycle exercise stress test. Table 1 shows anthropometric data and maximal exercise capacity. Maximal oxygen uptake was measured during treadmill exercise testing by an online system (MedGraphics CPX, St Paul, Minnesota, USA).

A control group of 12 sedentary or moderately physically active healthy men (mean (SD) age 74.5 (2.7) years) was studied. The controls were recruited from a local pensioners' club. They had no history of cardiovascular disease, were not taking medication, and had a normal bicycle exercise stress test. Maximal oxygen uptake was measured during cycling by an online system (SensorMedics 2900Z; SensorMedics, Anaheim, California, USA). 
Table 1 Anthropometric data, maximum exercise capacity, and echocardiography data

\begin{tabular}{lllc}
\hline & Athletes $(n=11)$ & Controls $(n=12)$ & p value \\
\hline Age (years) & $73.2(2.8)$ & $74.5(2.7)$ & 0.16 \\
Height $(\mathrm{cm})$ & $179(6)$ & $175(6)$ & 0.24 \\
Weight $(\mathrm{kg})$ & $73(9)$ & $79(11)$ & 0.18 \\
$\mathrm{BMI}\left(\mathrm{kg} / \mathrm{m}^{-2}\right)$ & $22.7(2.6)$ & $26.0(3.6)$ & 0.049 \\
$\mathrm{Max} \mathrm{VO}(1)$ & $2.91(0.52)$ & $2.10(0.29)$ & $<0.001$ \\
Max VO $\left(\mathrm{ml} / \mathrm{kg} / \mathrm{min}^{-1}\right)$ & $41(7)$ & $26(5)$ & $<0.001$ \\
Maximum exercise capacity (W) & $258(35)$ & $172(19)$ & $<0.001$ \\
Maximum exercise capacity (W/kg) & $3.6(0.4)$ & $2.2(0.4)$ & $<0.001$ \\
Left atrial diameter $(\mathrm{mm})$ & $38(3)$ & $41(6)$ & 0.27 \\
Left ventricular end diastolic diameter (mm) & $47(3)$ & $46(6)$ & 0.87 \\
Septal thickness (mm) & $11(1)$ & $11(1)$ & 0.79 \\
\hline
\end{tabular}

Exercise capacity measured with bicycle test. Echocardiography data from cross sectional images.

The experimental protocol was approved by the institutional ethics committee.

METHODS

A 12 lead resting electrocardiogram (ECG) was registered for each participant. Long term ECGs were made using a cassette based two channel ECG recorder (Reynolds Sherpa; Reynolds Medical, Hertford, UK). Electrode positions similar to V1 and V5 were used. The recording quality was checked for stability and the capability to detect $\mathrm{P}$ waves. Participants kept a diary for the registration period. All were monitored for 48 hours. The ECG signal was digitised and stored using a commercially available personal computer based system (Aspect Holter System; Daltek, Borlänge, Sweden). Automatic analysis of arrhythmias was made first and the QRS complexes classified. Recordings were checked manually by one of the authors.

One athlete with frequent ventricular extrasystoles was excluded from heart rate variability analysis. Consecutive RR intervals were expressed in centiseconds and their corresponding classification codes exported to an ASCII text file. Five minute (300 seconds) epochs of data were analysed in time and frequency domains by custom made software.
The time series of RR intervals were resampled at a frequency of two samples/second. Gaps in the time series due to non-normal RR intervals (QRS labelled by the Aspect Holter System classification as noise or extrasystoles) were filled with values calculated by linear interpolation between adjacent normal RR intervals. The computer program also automatically checked for misclassified dropped beats deviating more than three standard deviations from the mean normal RR interval of each epoch. Epochs with more than $4 \%$ non-normal RR intervals were excluded.

The frequency domain of the time series of $\mathrm{RR}$ intervals was analysed with an autoregressive spectral analysis, namely Burg's method. ${ }^{18}$ The model order and number of coefficients in the polynomial describing the time series were constantly set to 18 . The mean RR interval of each time series was subtracted and then detrended by linear regression. The power spectrum of the frequency domain was divided into four bands according to Bigger and colleagues $^{17}$; total power $0.0033-0.40 \mathrm{~Hz}$ $\left(\mathrm{ms}^{2}\right)$; very low frequency (VLF) power $0.0033-0.04 \mathrm{~Hz}$; low frequency (LF) power $0.04-0.15 \mathrm{~Hz}$; and high frequency $(\mathrm{HF})$ power $0.15-0.40 \mathrm{~Hz}$.

The biological mechanisms responsible for the VLF band are not fully understood. ${ }^{17} 1920$ VLF, however, is a strong, independent predictor for the outcome of different cardiovascular diseases. ${ }^{20} \mathrm{LF}$ is associated with baroreceptor function and blood pressure control. ${ }^{21-23} \mathrm{LF}$ mainly reflects the presence of sympathetic activity $^{212324}$; however, parasympathetic activity may also influence LF power. ${ }^{25}$ The HF band is mainly related to the parasympathetic activity of the sinus arrhythmia. ${ }^{2123}$

The different parameters were analysed for the whole 24 hour period for the day (0730-2130) and night (0000-0500).

Table 2 Results of 48 hour ambulatory electrocardiography

\begin{tabular}{|c|c|c|c|c|c|c|c|c|c|}
\hline $\begin{array}{l}\text { Subject } \\
\text { (age) } \\
\text { (years) }\end{array}$ & $\begin{array}{l}H R 4 R R \\
\text { (beats/min) }\end{array}$ & $\begin{array}{l}\text { HR } 1 \mathrm{~min} \\
\text { (beats } / \mathrm{min} \text { ) }\end{array}$ & $A V I I$ & $\begin{array}{l}V E S \\
(n o / 24 h)\end{array}$ & $\begin{array}{l}\text { Multiform } \\
\text { VES }\end{array}$ & $\begin{array}{l}\text { Ventricular } \\
\text { couplets }\end{array}$ & $R$ on $T$ & $V T$ & $\begin{array}{l}S V E S> \\
100 / 24 h\end{array}$ \\
\hline \multicolumn{10}{|c|}{ Veteran athletes } \\
\hline $1(77)$ & 37 & 48 & & 125 & $x$ & & & & $x$ \\
\hline $2(77)$ & 39 & 46 & & 22050 & $\times$ & $x$ & $\times$ & & \\
\hline $3(76)$ & 26 & 43 & Type 2 & 39 & $\times$ & $x$ & & & $\times$ \\
\hline $4(75)$ & 35 & 40 & & 2800 & & & & & $x$ \\
\hline $5(73)$ & 36 & 44 & & 5 & & $\times$ & & & $x$ \\
\hline $6(71)$ & 36 & 46 & & 33 & $x$ & $x$ & & & $x$ \\
\hline $7(71)$ & 40 & 52 & Type 1 & 158 & $x$ & $x$ & $\times$ & $\times(3$ beats $)$ & $x$ \\
\hline $8(71)$ & 38 & 54 & & 52 & $x$ & & & & $x$ \\
\hline $9(71)$ & 45 & 53 & & 33 & $x$ & & & & $x$ \\
\hline $10(71)$ & 44 & 53 & & 13 & & & & & $x$ \\
\hline $11(68)$ & 44 & 49 & & 12 & $\times$ & $\times$ & & & \\
\hline \multicolumn{10}{|l|}{ Controls } \\
\hline $1(79)$ & 54 & 55 & & 2 & & & & & \\
\hline $2(78)$ & 44 & 57 & Type 1 & 8 & & & & & \\
\hline $3(78)$ & 49 & 51 & & 17 & & & & $\times(5$ beats $)$ & \\
\hline $4(75)$ & 40 & 52 & & 2 & & & & & $x$ \\
\hline $5(75)$ & 42 & 52 & & 37 & $\times$ & & & & $x$ \\
\hline $6(75)$ & 56 & 61 & & 48 & & $\times$ & & $\times(4$ beats $)$ & $x$ \\
\hline $7(74)$ & 47 & 53 & & 76 & & $x$ & & & $x$ \\
\hline $8(74)$ & 41 & 48 & & 12 & & & & & \\
\hline $9(73)$ & 58 & 59 & & 1 & & & & & \\
\hline $10(72)$ & 45 & 53 & & 3 & & & & & \\
\hline $11(71)$ & 48 & 52 & & 69 & $x$ & $\times$ & & & \\
\hline $12(70)$ & 42 & 56 & & 71 & & & & & \\
\hline
\end{tabular}

All subjects were in sinus rhythm.

HH 4 RR, lowest heart rate calculated from 4 RR intervals; HR 1 min, lowest heart rate during 1 minute; VES, ventricular extrasystoles; SVES, supraventricular extrasystoles. 
Table 3 Heart rate variablility

\begin{tabular}{|c|c|c|c|c|c|c|}
\hline & $\begin{array}{l}\text { Heart rate } \\
\text { (beats } / \text { min) }\end{array}$ & $\begin{array}{l}\text { Total power } \\
\left(m s^{2}\right)\end{array}$ & $\begin{array}{l}V L F \\
\left(m s^{2}\right)\end{array}$ & $\begin{array}{l}L F \\
\left(m s^{2}\right)\end{array}$ & $\begin{array}{l}H F \\
\left(m s^{2}\right)\end{array}$ & $L F / H F$ \\
\hline \multicolumn{7}{|l|}{ Whole period } \\
\hline Athletes & $60(6)$ & $1971(609)$ & $944(284)$ & $673(244)$ & 353 (349) & $3.07(1.30)$ \\
\hline Controls & $69(4)$ & $1370(447)$ & $668(173)$ & $492(290)$ & 209 (172) & $3.30(1.27)$ \\
\hline $\mathrm{p}$ value & 0.008 & 0.034 & 0.032 & 0.089 & 0.125 & 0.710 \\
\hline \multicolumn{7}{|c|}{ Night (0000-0500) } \\
\hline Athletes & $53(5)$ & $2102(964)$ & $863(267)$ & $764(327)$ & $475(654)$ & $3.07(1.77)$ \\
\hline Controls & $59(3)$ & $1945(739)$ & 889 (398) & $728(485)$ & $328(48)$ & $3.26(1.96)$ \\
\hline $\mathrm{p}$ value & 0.011 & 0.770 & 0.983 & 0.697 & 0.608 & 0.823 \\
\hline \multicolumn{7}{|c|}{ Day $(0730-2130)$} \\
\hline Athletes & $66(9)$ & $1788(577)$ & $934(331)$ & $587(250)$ & 267 (163) & $3.05(1.34)$ \\
\hline Controls & $76(7)$ & $1013(342)$ & $539(152)$ & $346(177)$ & $127(41)$ & $3.44(0.82)$ \\
\hline $\mathrm{p}$ value & 0.013 & 0.005 & 0.009 & 0.021 & 0.010 & 0.491 \\
\hline
\end{tabular}

Frequency domain measures of RR variability in male veteran athletes and healthy controls obtained from 48 hour ambulatory ECGs. Values are mean (SD).

Total power, $0.0033-0.40 \mathrm{~Hz},\left(\mathrm{~ms}^{2}\right)$; VLF, very low frequency power, 0.0033-0.04 Hz; LF, low frequency power, 0.04-0.15 Hz; HF, high frequency power, $0.15-0.40 \mathrm{~Hz}$.

\section{STATISTICS}

Non-normal distributed values were logarithmically transformed before analysis. Significance was tested with either the Student's two tailed unpaired $t$ test or the $\chi^{2}$ test when applicable. A $p$ value $<0.05$ was considered significant.

\section{Results}

RESTING ECG AND EXERCISE STRESS TEST

One of the 11 elderly athletes had first degree atrioventricular (AV) block with a PR interval of 0.26 seconds. Three athletes had ST elevation in at least one of the precordial leads of more than $2 \mathrm{~mm}$. One athlete had left bundle branch block.

Five athletes had junctional ST depression of more than $1 \mathrm{~mm}$ during exercise that disappeared immediately after exercise. None had horizontal or downsloping ST segment depression. One athlete had frequent ventricular extrasystoles at rest and during exercise and another had frequent ventricular extrasystoles at the highest workload. All patients stopped exercise due to fatigue, none had chest pain.

\section{ARRHYTHMIAS}

Seven athletes but none of the controls had a heart rate below 40 beats $/ \mathrm{min}$ at some point during the night (table 2). Two athletes had RR intervals longer than two seconds: 2.3 seconds in sinus rhythm in one and 2.6 seconds during second degree AV block in the other. One control had an episode of second degree sinoatrial block with an RR interval of 2.3 seconds. Two athletes and one control had intermittent second degree AV block at night. Nine athletes and five controls $(p<0.05)$ had complex ventricular arrhythmias at some time during registration, either couplets, multiform ventricular beats, or ventricular tachycardia. There was no relation between the amount of training (hours/week) and complex ventricular tachycardias; athletes who trained more than others did not have more arrhythmias. Two athletes and three controls had short supraventricular tachycardias.

\section{HEART RATE VARIABILITY}

Mean heart rate in athletes was lower than in the controls $(\mathrm{p}<0.05)$ (table 3$)$. The athletes had higher heart rate variability than the controls for the whole period and day time but not at night.

\section{Discussion}

The elderly athletes had a high incidence of complex ventricular arrhythmias. Furthermore, they also had profound bradyarrhythmias at night.

Fleg and Kennedy ${ }^{26}$ who investigated the occurrence of arrhythmias in 98 healthy men and women aged between 60 and 85 years reported that profound bradycardia (defined as heart rate calculated from four RR intervals below 40 beats/min) and long sinus pauses ( $>1.5$ seconds) were rare. In their study half the population had complex ventricular arrhythmias (defined earlier). Bjerregaard ${ }^{27}$ studied 76 healthy men and women aged 60-79 years and found complex ventricular arrhythmias in 34. A similar percentage was observed in our study in which five of 12 healthy 70-80 year old men had ventricular arrhythmias. Grimby and Saltin ${ }^{6}$ who studied 33 middle aged athletes found only three with ventricular extrasystoles and two with AV block. In our group, nine of 11 athletes had complex ventricular arrhythmias. From our findings it seems that elderly athletes have a higher incidence of complex ventricular arrhythmias and more profound bradyarrhythmias than non-athletes. Moreover, the athletes also had a higher incidence of, and more complex, ventricular arrhythmias than those found in young runners who had very few ventricular or supraventricular extrasystoles. ${ }^{14}$ There was no relation between the amount of training and the incidence of complex ventricular tachycardias. We cannot, however, say if there is a relation between total training load during an entire lifetime and arrhythmias.

The present findings indicate that lifelong strenuous training may increase the incidence of ventricular arrhythmias. An increased incidence of ventricular arrhythmias is associated with diminished long term survival in postinfarction patients. ${ }^{28}$ However, the relation between ventricular arrhythmias and sudden cardiac death in patients without evident heart disease is controversial. ${ }^{29}$ 
As outlined earlier all spectral variables of heart rate variability decrease with age $\mathrm{e}^{17}{ }^{30}$ and a similar age dependent decrease is found in other autonomic function tests such as the deep breathing test. ${ }^{16}$ Autonomic test results of normal individuals up to 85 years of age decrease continuously with advancing age. ${ }^{31}$ Other tests of autonomic function show a more rapid decrease in individuals older than $60 .{ }^{32}$ Elderly athletes in the present study had higher heart rate variability than the controls. Heart rate variability was as high as in healthy $60-69$ year old men, ${ }^{30}$ which suggests that regular strenuous exercise can retard the age related decrease in heart rate variability. Possible similar effects in other autonomic function tests in this group remain to be studied. This finding resembles that in young elite runners who also have higher heart rate variability than normal age matched individuals. ${ }^{14}$

We could not find a relation between heart rate variability and arrhythmias in our elderly athletes. None had low heart rate variability.

We conclude that elderly male athletes with a lifelong history of training seem to have more complex arrhythmias and profound bradyarrhythmias than do healthy elderly controls, which may increase the risk of sudden cardiac death. In contrast, the age related decrease in heart rate variability appears to be retarded, which has a positive prognostic value and may decrease the risks of life threatening ventricular arrhythmias.

This study was supported by grants from the Swedish Centre of Research in Sports and the Swedish Orienteering Federation. Research in Sports and the Swedish Orienteering Federation.
We thank Liselott Söderström and Kerstin Nilsson for skilful technical assistance.

Blomqvist CG, Saltin B. Cardiovascular adaptations to physical training. Annu Rev Physiol 1983;45:169-89.

physical training. Annu Rev Physiol $1983 ; 45: 169-89$.
Folkow B, Svanborg A. Physiology of cardiovascular aging. Physiol Rev 1993;73:725-64.

3 Paffenberger Jr RS, Hyde RT, Wing AL, et al. Physical activity, all-cause mortality, and longevity of. college alumni. $N$ Engl f Med 1986;314:605-14.

4 Berlin JA, Colditz GA. A meta-analysis of physical activity in the prevention of coronary heart disease. Am $\mathcal{F}$ Epidemio 1990;132:612-28.

5 Siscovick DS, Weiss NS, Fletcher RH, et al. The incidence of primary cardiac arrest during vigorous. exercise. $N$ Engl f Med 1984;311:874-7.

6 Grimby G, Saltin B. Physiological analysis of physically well-trained middle-aged and old athletes. Acta Med Scand 1996;179:513-26.

7 Northcote RJ, Canning GP, Ballantyne D. Electrocardiographic findings in male veteran endurance athletes. $\mathrm{Br}$ Heart $\mathcal{F}$ 1988;61:155-60.

8 Kamath MV, Fallen EL. Power spectral analysis of heart rate variability: a noninvasive signature of cardiac autonomic variability: a noninvasive signature of cardiac a
function. Crit Rev Biomed Eng 1993;21:245-311.
9 Kleiger RE, Miller JP, Bigger JT Jr, et al. Decreased heart rate variability and its association with. increased mortality after acute myocardial infarction. Multicenter PostInfarction Research Group. Am f Cardiol 1987;59:256-62.

10 Cripps TR, Malik M, Farrell TG, et al. Prognostic value of reduced heart rate variability after myocardial. infarction: clinical evaluation of a new analysis method. Br Heart 7 1991;69:14-19.

11 Farrell TG, Odemuyiwa O, Bashir Y, et al. Prognostic value of baroreflex sensitivity testing after acute myocardial infarction. Br Heart f 1992;67:129-37.

12 Puig J, Freitas J, Carvalho MJ, et al. Spectral analysis of heart rate variability in athletes. $\mathcal{F}$ Sports Med Phys Fitness 1993;33:44-8.

13 De Meersman RE. Heart rate variability and aerobic fitness. Am Heart f 1993;125:726-31.

14 Jensen-Urstad K, Eriksson M, Saltin B, et al. Pronounced resting bradycardia in male elite runners is associated with increased heart rate variability. Scand $\mathcal{f}$ Med Sci Sports 1997;5:274-8.

15 Sacknoff DM, Gleim GW, Stachenfeld N, et al. Effect of athletic training on heart rate variability. Am Heart f 1994; 127:1275-8.

16 Bergström B, Lilja B, Rosberg $\mathrm{K}$, et al. Autonomic nerve function tests. Reference values in healthy subjects. Clin Physiol 1986;6:523-8.

17 Bigger TJ Jr, Fleiss JL, Steinman RC, et al. RR variability in healthy, middle-aged persons compared with patients with chronic coronary heart disease or recent acute myocardial infarction. Circulation 1995;91:1936-43.

18 Burg JP. Maximum entropy spectral analysis. Proceedings of the 37th meeting of the Society of Exploration Geophysicists, 1967.

19 Kitney RI. The analysis and simulation of the human thermoregulatory control system. Med Biol Eng 1973;1:57-64.

20 Malik M, Camm AJ. Heart rate variability. Clin Cardiol 1990;13:570-6.

21 Akselrod S, Gordon D, Ubel FA, et al. Power spectrum analysis of heart rate fluctuation: a quantitative probe of beat to beat cardiovascular control. Science 1981;213:2202 .

22 Katona PG, Jih F. Respiratory sinus arrhythmia: noninvasive measure of parasymphatetic control. F Appl Physiol 1975;39:801-5.

23 Pomeranz B, Macaulay RJB, Caudill MA, et al. Heart rate and muscle symphatetic nerve variability during reflex changes of autonomic activity. Am F Physiol 1990;258:71318.

24 Pagani M, Lombardi F, Guzetti S, et al. Power spectral analysis of heart rate and arterial pressure variabilities as a marker of sympatho-vagal interaction in man and conscious dog. Circ Res 1986;58:178-93.

25 Saul JP, Rea RF, Eckberg DL, et al. Heart rate and muscle sympathetic nerve variability during reflex changes of autonomic activity. Am f Physiol 1990;258:713-21.

26 Fleg JL, Kennedy HL. Cardiac arrhythmias in a healthy elderly population. Circulation 1982;81:302-7.

27 Bjerregaard P. Premature beats in healthy subjects $40-79$ years of age. Eur Heart $\mathcal{F}$ 1982;3:493-503.

28 Ruberman W, Wiinblatt E, Goldberg JD, et al. Ventricular premature complexes and sudden death after myocardial infarction. Circulation 1981;64:297-305.

29 Abdalla IS, Prineas RJ, Neaton JD, et al. Relation between ventricular premature complexes and sudden cardiac death in apparently healthy men. Am $\mathcal{F}$ Cardiol $1987 ; 60: 1036-42$.

30 Jensen-Urstad K, Storck N, Bouvier F, et al. Heart rate variability in healthy subjects is related to age and gender. Acta Physiol Scand 1997;160:235-41.

31 O'Brien I, O'Hare P, Corrall RJM. Heart rate variability in healthy subjects: effect of age and the derivation of normal ranges for tests of autonomic function. Br Heart f 1986;55: 348-54.

32 Kaijser L, Sachs C. Autonomic cardiovascular responses in old age. Clin Physiol 1985;5:347-57. 